\title{
INFLUENCE OF EMOTIONAL DETERMINANTS ON THE FOOD CHOICES OF THE PORTUGUESE
}

\author{
Raquel P. F. Guiné $\boldsymbol{e}^{l}$ \\ raquelguine@esav.ipv.pt
}

Ana Cristina Ferrão ${ }^{l}$

Paula Correia ${ }^{1}$

Ana Paula Cardoso ${ }^{l}$

Manuela Ferreira ${ }^{l}$

João Duarte ${ }^{1}$

${ }^{I}$ CI\&DETS Research Centre

Polytechnic Institute of Viseu

Av. Cor. José Maria Vale de Andrade s/n, Campus Politécnico Santa Maria,

Viseu, Portugal, 3504-510

\begin{abstract}
Food choices are influenced by many factors, such as emotional. When people eat, driven by emotional factors, they often lose control, which may lead to eating disorders. Therefore, this work aimed at studying the influence that emotional determinants had on people's food choices. It was undertaken a descriptive cross-sectional study by means of a questionnaire on a non-probabilistic sample of 1314 participants. The data was collected among a sample of the Portuguese population and measured if people's food choices were influenced by emotional determinants.

The results revealed that the participants' food choices were, in general, slightly influenced by emotional determinants (mean scores between -0.5 and 0.5 , on a scale from -2 to +2 ). There were found significant differences in all of the variables under study. The participants, who already experienced an episode of binge-eating, were the ones that obtained the highest mean score $(0.63 \pm 0.79)$, meaning that in this case those participants' food choices were influenced by emotional determinants. These results support the premise that emotional determinants are influenced by the characteristics of each individual and also the existence of a positive association between emotional eating and the presence of eating disorders, especially, binge-eating.
\end{abstract}

Keywords: Eating disorders, emotional determinants, emotional eating, food choices, individual characteristics, survey.

DOI: 10.21303/2504-5571.2019.00995

\section{Introduction}

Food consumption is essential for people's survival, and food choices are a daily task [1]. However, food choice behaviour is complex and influenced by different factors, such as for example, hunger, cost, accessibility, culture, peers and emotions [2]. In fact, emotions have a uniquely important role in food consumption and the relation between food and mood has been the subject of many scientific studies [3]. How emotions affect food behaviour varies according to the particular characteristics of the individual and the emotional states involved [4]. For example, restrained eaters tend to consume more food in response to fear and negative mood states, while the opposite occurs in the case of non-restrained eaters [5]. Furthermore, many people eat in order to distract themselves, compensate something, or to deal with negative effects such as stress, anxiety, frustration, fear, daily issues, sadness, boredom, depression and fatigue [6]. The foods, eaten under these circumstances, are called comfort foods, because they provide consolation or a feeling of well-being [7]. According to Locher et al. [8], comfort foods are usually familiar to the individual and used only on special occasions, most notably when feeling sad, depressed or when alone. They may also evoke feelings of nostalgia, they are usually prepared in a simple or traditional style, are often indulgent, and typically provide a sense of both physical and emotional comfort. 
Emotional eating is defined as the tendency to eat more in response to negative emotions $[9,10]$ and it is a risk factor for the development of many eating pathologies, such as binge-eating disorder, bulimia nervosa and food cravings $[11,12]$. Several studies showed that emotional eating is associated with unhealthy lifestyles, characterized by the consumption of high-calorie and high fat foods, poor weight loss outcomes, weight gain and obesity [13-15]. Furthermore, in another study by Wong and Qian (2016), it has also been shown, that shame, as a self-conscious emotion, played an important role in emotional eating. Because emotional eating is highly relevant due to its possible negative effects on health, and given the lack of information about this topic in the Portuguese population, it is crucial to understand in what way emotional factors influence consumers' food choices.

This study is included in the multinational project, entitled "Psycho-social motivations, associated with food choices and eating practices (EATMOT)" which aims to perform a research about some psychic and social motivations that determine people's dietary patterns in relation to their choices or eating habits.

The main goal of this particular research was to evaluate in what extent the participants' food choices were influenced by emotional determinants, especially among the participants who had already experienced an episode of any eating disorder and those, who never had, for a sample of the Portuguese population. It was also analysed, in what way emotional determinants are affected by other individual characteristics, such as for example, the level of education and the Body Mass Index (BMI) class.

\section{Materials and methods}

\section{1. Instrument}

To undertake this study, there was purposely created a questionnaire, based on a review of other instruments [16-22]. The questionnaire used was composed of different parts, intended to access different information about the sample at study: Part I - Sociodemographic data; Part II Anthropometric data and eating behavioural related elements; Part III - Emotional determinants. In order to measure the emotional determinants, the participants were asked to indicate their accordance to the following questions, measured on a scale ranging from 1 to 5 (1 - totally disagree, 2 - disagree, 3 - neither agree nor disagree, 4 - agree and 5 - strongly agree):

1. Food helps me cope with stress.

2. I usually eat food that helps me control my weight.

3. I often consume foods that keep me awake and alert (such as coffee, coke, energy drinks).

4. I often consume foods that helps me relax (such as some teas, red wine).

5. Food makes me feel good.

6. When I feel lonely, I console myself by eating.

7. I eat more when I have nothing to do.

8. For me, food serves as an emotional consolation.

9. I have more cravings for sweets when I am depressed.

\section{2. Data collection}

It was undertaken a descriptive cross-sectional study on a non-probabilistic sample of 1314 participants living in Portugal. The questionnaires were applied between January and December 2017 only to adults (aged 18 or over) and after verbal informed consent. All ethical issues were followed when designing and applying the questionnaire, which was approved by the Ethical Committee with reference $n^{\circ} 04 / 2017$.

\section{3. Statistical analysis}

For the exploratory analysis of the data, basic descriptive statistics tools were used. In all tests the level of significance considered was $5 \%$ and all data analysis was made using the software IBM SPSS (version 25). For analysing the differences between the quantitative variables among groups, the non-parametric tests were used, namely, the Mann Whitney and the Kruskal-Wallis tests, for comparisons between two groups and for comparisons between three or more groups, 
respectively. In case on the Kruskal-Wallis test, multiple comparisons were performed between the groups, using the pairwise method. Also the crosstabs and the chi square test were used to assess the relations between some of the categorical variables. To evaluate the strength of the significant relations, found between some of the variables at study, it was used the Cramer's V coefficient, which varies from 0 to 1 , and for $\mathrm{V} \approx 0.1$ the association is considered weak, for $\mathrm{V} \approx 0.3$ the association is moderate and for $\mathrm{V} \approx 0.5$ or over, the association is strong [23].

The relations between the different variables selected and the influence of emotional determinants on participants' food choices were analysed through the average of the scores, obtained for all the items, included in part III of the questionnaire. However, for that, it was necessary, that the average was not influenced by the score attributed to the mean point of the Likert scale $(3=$ neither agree nor disagree). Hence, the items were recoded into a new scale, ranging from -2 to $+2(-2$ : totally disagree, -1 : disagree, 0 : neither agree nor disagree, 1: agree and 2: strongly agree). Then, these scores were used to calculate the average score, obtained for each participant, thus giving the variable influence of emotional determinants on food choices. This variable had values between -2 and +2 , interpreted as follows: $[-2.0 ;-1.5[-$ food choices, not at all influenced by emotional determinants; $[-1.5 ;-0.5$ [- food choices, not influenced by emotional determinants; $[-0.5 ; 0.5[-$ food choices, slightly influenced by emotional determinants; $[0.5 ; 1.5[$ - food choices, influenced by emotional determinants; $[1.5 ; 2.0]$ - food choices, strongly influenced by emotional determinants.

\section{Results}

\section{1. Sample characterization}

The sample consisted of 1314 participants, living in Portugal, aged between 18 and 84, being on average $37.4 \pm 14.7$ years. The women, who participated in this study, were, in general, younger (35.8 \pm 14.1 years) than men ( $40.5 \pm 15.4$ years). Most of the participants, $40.5 \%$, were in the age class, corresponding to young adults (Table 1). Regarding gender, $67.0 \%$ of the participants were women, while only $33.0 \%$ were men. Among the participants, $49.8 \%$ were married or lived as a marital couple, $40.2 \%$ were single, $5.6 \%$ were divorced or separated and only $4.4 \%$ were widowed.

Regarding the level of education, more than a half of the participants $(56.6 \%)$ had a university degree, $43.2 \%$ had completed secondary school and only $0.2 \%$ had the primary school as the highest level of education achieved.

Table 1 further shows that $60.4 \%$ of the participants were employed. $29.1 \%$ were students, $5.1 \%$ working students, $3.1 \%$ retired and $2.4 \%$ were unemployed. It was also observed, that $14.4 \%$ of the participants worked or had studies in health areas, $66.2 \%$ of them had a profession or studies, related to other areas, and only a few percentage of the participants had a professional activity or studies, related to the particular areas, suggested in the questionnaire (nutrition, food, agriculture, sport and psychology).

When the participants were asked about their living environment, $76.7 \%$ of them answered that they lived in an urban surrounding, $16.4 \%$ in a rural environment and $6.9 \%$ lived in a suburban area. Furthermore, only $7.0 \%$ of the participants indicated that they were not responsible for buying their own food.

Table 1

Sociodemographic characterization of the sample at study

\begin{tabular}{ccc}
\hline & Sociodemographic variables & Percentage (\%) \\
\hline $\mathbf{1}$ & $\mathbf{2}$ & $\mathbf{3}$ \\
\hline \multirow{2}{*}{ Age } & $18 \mathrm{y} \leq \mathrm{age} \leq 30 \mathrm{y}$ & 40.5 \\
& $31 \mathrm{y} \leq \mathrm{age} \leq 50 \mathrm{y}$ & 38.1 \\
& $51 \mathrm{y} \leq \mathrm{age} \leq 64 \mathrm{y}$ & 17.3 \\
\multirow{2}{*}{ Gender } & Age $\geq 65 \mathrm{y}$ & 4.2 \\
& Women & 67.0
\end{tabular}


Continuation of Table 1

\begin{tabular}{ccc}
\hline $\mathbf{1}$ & $\mathbf{2}$ & $\mathbf{3}$ \\
\hline \multirow{2}{*}{ Highest Level of Education } & Primary School & 0.2 \\
& Secondary School & 43.2 \\
& University Degree & 56.6 \\
Civil State & Single & 40.2 \\
& Married/Living Together & 49.8 \\
& Divorced/Separated & 5.6 \\
& Widow & 4.4 \\
Profession & Employed & 60.4 \\
& Unemployed & 2.4 \\
& Student & 29.1 \\
& Retired & 3.1 \\
& Working student & 5.1 \\
& Nutrition & 2.8 \\
& Food & 6.9 \\
Area of work or study & Agriculture & 3.2 \\
& Sport & 4.2
\end{tabular}

\section{2. Anthropometric data and behavioural related elements}

Table 2 presents an anthropometric characterization of the sample at study, and the results showed that the average height of the participants was $1.69 \pm 0.09$ meters. As for weight, the mean score was $63.59 \pm 10.8 \mathrm{~kg}$. From the self-reported values, BMI was calculated as weight $(\mathrm{kg})$, divided by the square of height $\left(\mathrm{m}^{2}\right)$ and classified, according to the standards of the International Classification: underweight $\left(\mathrm{BMI}<18.50 \mathrm{~kg} / \mathrm{m}^{2}\right)$, normal weight $\left(18.50 \leq \mathrm{BMI} \leq 24.99 \mathrm{~kg} / \mathrm{m}^{2}\right)$, overweight $\left(25.00 \leq \mathrm{BMI} \leq 29.99 \mathrm{~kg} / \mathrm{m}^{2}\right)$ and obese $\left(\mathrm{BMI} \geq 30.00 \mathrm{~kg} / \mathrm{m}^{2}\right)$ [24]. Thus, BMI scores ranged from 16.09 to $43.56 \mathrm{~kg} / \mathrm{m}^{2}$ with an average equal to $22.25 \pm 3.3 \mathrm{~kg} / \mathrm{m}^{2}$, which means, that on average the participants had a normal weight. When seen by gender, it was observed, that the average values for women were lower than for men, with significant differences between genders.

Table 2

Anthropometric characteristics of the sample according to gender

\begin{tabular}{ccccc}
\hline $\begin{array}{c}\text { Anthropometric } \\
\text { measures }\end{array}$ & Global & Women & Men & p-value $^{\mathbf{1}}$ \\
\hline Weight $(\mathrm{kg})$ & $63.59 \pm 10.8$ & $59.87 \pm 9.0$ & $71.16 \pm 10.2$ & $<0.0005$ \\
Height $(\mathrm{m})$ & $1.69 \pm 0.06$ & $1.65 \pm 0.07$ & $1.78 \pm 0.06$ & $<0.0005$ \\
BMI $\left(\mathrm{kg} / \mathrm{m}^{2}\right)$ & $22.25 \pm 3.3$ & $22.10 \pm 3.4$ & $22.56 \pm 3.1$ & 0.001
\end{tabular}

Note: ${ }^{1}$ - p-value for the comparison between male and female

Table 3 presents the voluntary dietary regimen, practiced by the participants and $86.0 \%$ of them indicated that did not follow any specific food regimen, with a higher percentage of men $(93.3 \%)$, adopting a general dietary pattern when compared to women $(82.4 \%)$. On the other hand, the higher percentage of the female participants followed a caloric restriction (9.2\%) than the equivalent percentage of the male participants (7.2\%). The results of the Chi-square test proved that the food regimen adopted was influenced by gender $(p<0.0005)$, although with a weak association between the variables $(\mathrm{V}=0.145)$. These findings are in line with previous scientific evidences, 
where it was established, that dieting to lose weight is a practice more common among women than men [25-28].

Table 3

Voluntary dietary regimen practice by the participants, according to gender

\begin{tabular}{cccccc}
\hline \multirow{2}{*}{$\begin{array}{c}\text { Specific dietary } \\
\text { regimen }\end{array}$} & Global & Women & Men & Chi square test $^{1}$ & Cramer's Coefficient $^{\mathbf{2}}$ \\
\cline { 2 - 5 } & $\mathbf{\%}(\mathbf{N})$ & $\mathbf{\%}(\mathbf{N})$ & $\mathbf{\%}(\mathbf{N})$ & p-value & V \\
\hline Raw foodism & $0.0(0)$ & $0.0(0)$ & $0.0(0)$ & & \\
Fruitarianism & $0.2(3)$ & $0.2(2)$ & $0.2(1)$ & & \\
Vegetarianism & $3.4(44)$ & $4.3(38)$ & $1.4(6)$ & & \\
Veganism & $0.5(6)$ & $0.7(6)$ & $0.0(0)$ & & \\
Flexitarianism & $1.1(15)$ & $1.5(13)$ & $0.5(2)$ & & \\
Caloric restriction & $7.2(95)$ & $9.2(81)$ & $3.2(14)$ & & \\
Religious restriction & $0.5(6)$ & $0.5(4)$ & $0.5(2)$ & & \\
Other & $1.1(15)$ & $1.3(11)$ & $0.9(4)$ & & \\
None & $86.0(1129)$ & $82.4(725)$ & $93.3(404)$ & &
\end{tabular}

Note: ${ }^{1}$ - Used to assess the relations between the variables under study (level of significance $5 \%$ ); ${ }^{2}$ - Used to evaluate the strength of the significant relations, found between the variables at study

As it can be observed in Table 4, the majority of the participants answered that they never experienced an episode of any eating disorder $(96.4 \%)$, with the higher percentage of men (98.6\%) indicating that, when compared to women $(95.3 \%)$. As it was expected, these differences between genders were significant, meaning that gender influenced the variable eating disorders $(\mathrm{p}<0.0005)$, although, the values of Cramer's coefficient indicated that this association was weak ( $\mathrm{V}=0.155)$. In fact, it is more likely that women adopt dietary compensatory behaviours than men [29]. Also the $B M I$ class has proven to influence the fact that the participants had already experienced an episode of any eating disorder $(\mathrm{p}<0.0005)$ and the people underweighted tended to be more predisposed to have already suffered from anorexia nervosa. It was also observed, that the participants, who were obese, had more tendency to suffer from binge-eating. Nevertheless, once again the association between the variables was weak ( $\mathrm{V}=0.133)$. According to several studies, eating disorders are associated with relative body weight, more specifically, anorexia nervosa is associated with underweight and binge-eating is usually associated with obesity [30-34].

Table 4

Participants' eating disorders

\begin{tabular}{|c|c|c|c|c|c|}
\hline \multirow{2}{*}{ Eating disorders } & Global & Women & Men & Chi square test ${ }^{1}$ & Cramer's Coefficient $^{2}$ \\
\hline & $\%(N)$ & $\%(N)$ & $\%(\mathrm{~N})$ & p-value & $\mathbf{V}$ \\
\hline Bulimia & $0.4(5)$ & $0.6(5)$ & $0.0(0)$ & & \\
\hline Anorexia & $1.5(20)$ & $1.9(17)$ & $0.7(3)$ & & \\
\hline Binge-eating & $1.3(17)$ & $1.6(14)$ & $0.7(3)$ & $<0.0005$ & 0.155 \\
\hline Other & $0.4(0.4)$ & $0.6(5)$ & $0.0(0)$ & & \\
\hline None & $96.4(1267)$ & $95.3(840)$ & $98.6(427)$ & & \\
\hline
\end{tabular}

\section{3. Emotional determinants}

Table 5 presents the participants' opinions about the emotional determinants, underlying food choices and as it can be observed, an important part of the sample admitted that they consume foods for emotional reasons. For example, $46.6 \%$ agreed that they often consume foods that help them to relax, although still $50.6 \%$ of the participants disagreed with the statement "Food helps 
me cope with stress". Another example is the fact that $70.0 \%$ agreed that "Food makes me feel good", although a significant percentage of the participants disagreed with the following statements: "When I feel lonely, I console myself by eating" - $54.2 \%$, "I eat more when I have nothing to do" $-40.7 \%$, "For me, food serves as an emotional consolation" $-50.8 \%$, "I have more cravings for sweets when I am depressed" - $46.2 \%$.

Table 5

Participants' opinions regarding the statements included in part III of the questionnaire

\begin{tabular}{|c|c|c|c|c|c|}
\hline \multirow{2}{*}{ Statements included in part III } & \multicolumn{5}{|c|}{ Scale $^{1}$} \\
\hline & $1(\%)$ & $2(\%)$ & $3(\%)$ & $4(\%)$ & $5(\%)$ \\
\hline 1. Food helps me cope with stress & 8.3 & 50.6 & 18.0 & 19.8 & 3.3 \\
\hline 2. I usually eat food that helps me control my weight & 1.5 & 12.0 & 17.7 & 59.4 & 9.4 \\
\hline $\begin{array}{l}\text { 3. I often consume foods that keep me awake and alert } \\
\text { (such as coffee, coke, energy drinks) }\end{array}$ & 37.5 & 34.2 & 8.1 & 16.1 & 4.1 \\
\hline $\begin{array}{l}\text { 4. I often consume foods that helps me relax } \\
\text { (such as some teas, red wine) }\end{array}$ & 5.0 & 14.8 & 16.8 & 46.6 & 16.8 \\
\hline 5. Food makes me feel good & 1.0 & 3.6 & 16.4 & 70.0 & 9.1 \\
\hline 6. When I feel lonely, I console myself by eating & 22.1 & 54.2 & 12.3 & 9.3 & 2.1 \\
\hline 7. I eat more when I have nothing to do & 17.1 & 40.7 & 12.5 & 25.4 & 4.4 \\
\hline 8. For me, food serves as an emotional consolation & 20.3 & 50.8 & 12.8 & 12.5 & 3.5 \\
\hline 9. I have more cravings for sweets when I am depressed & 21.0 & 46.2 & 10.4 & 16.7 & 5.6 \\
\hline
\end{tabular}

Note: ${ }^{1}$ - Scale: 1 (totally disagree), 2 (disagree), 3 (neither agree nor disagree), 4 (agree) and 5 (strongly agree)

\section{3. 1. Sociodemographic characteristics}

The mean score, obtained for the influence of emotional determinants on participants' food choices, was equal to $-0.31 \pm 0.65$, meaning that, in general, the participants' food choices were slightly influenced by those determinants.

As it is shown in Table 6, there were found significant differences among age classes $(p<0.0005)$, regarding the influence of emotional determinants on food choices, with the young adults, obtaining the highest mean score $(-0.15 \pm 0.72)$. More specifically, according to the results of the Post-Hoc tests, those differences were between the elderly and the other age classes (elderly senior adults: $p=0.013$; elderly - average adults: $p=0.005$; elderly - young adults: $p=0.001$ ), as well as between the senior adults and the young adults $(\mathrm{p}<0.0005)$ and also between the average adults and the young adults $(\mathrm{p}<0.0005)$. In the case of the young, average and senior adults, their food choices were slightly influenced by emotional determinants. As for the elderly, the results showed that their food choices were not influenced by emotional determinants $(-0.67 \pm 0.46)$.

Regarding gender, as it was expected, were found significant differences $(p=0.001)$, and the results suggested that women are more influenced by emotional determinants when making their food choices. However, since the mean values were between -0.5 and 0.5 (men: $-0.40 \pm 0$. 54, women: $-0.26 \pm 0.69$ ), in both cases, the participants' food choices were slightly influenced by emotional determinants.

For the sample at study, it was observed, that the participants that had completed secondary school, were those, who achieved the highest score for the influence of emotional determinants on food choices $(-0.21 \pm 0.69)$, followed by the participants with a university degree $(-0.38 \pm 0.60)$ and finally the participants with the lowest level of education (primary school) as their terminal education $(-1.06 \pm 0.27)$. Furthermore, there were found significant differences among the different levels of education, concerning the extent to which food choices were influenced by emotional determinants. More specifically the differences were between the participants with a university degree and those who had secondary school as the highest level of education achieved $(\mathrm{p}<0.0005)$.

Marital status tend to influence people's dietary patterns, with emotional eating and overeating more likely to occur when individuals are alone $[35,36]$. Hence, not surprisingly, the highest 
mean score achieved was for the single participants $(-0.12 \pm 0.03)$. However, the mean scores of the single, married/living together and the divorced/separated participants were between -0.5 and 0.5 , which indicate that the food choices of those participants were slightly influenced by emotional determinants. In contrast, the mean value for the widowed was equal to $-0.54 \pm 0.38$, meaning that the food choices of those participants were not influenced by emotional determinants. Moreover, there were found significant differences between the different civil states, regarding the influence that emotional determinants had on participants' food choices, being those differences between the widowed and the single participants $(\mathrm{p}<0.0005)$.

\section{Table 6}

Relations between some sociodemographic characteristics and the emotional determinants (scale from $-2=$ food choices not at all influenced by emotional determinants to $+2=$ food choices, strongly influenced by emotional determinants)

\begin{tabular}{|c|c|c|c|}
\hline \multicolumn{2}{|c|}{ Variable } & \multirow{2}{*}{$\begin{array}{c}\text { Mean } \pm \text { SD } \\
-0.15 \pm 0.72\end{array}$} & \multirow[t]{2}{*}{ p-value } \\
\hline \multirow{4}{*}{ Age group } & $18 \mathrm{y} \leq$ age $\leq 30 \mathrm{y}$ & & \\
\hline & $31 \mathrm{y} \leq \mathrm{age} \leq 50 \mathrm{y}$ & $-0.39 \pm 0.59$ & \multirow{3}{*}{$<0.0005$} \\
\hline & $51 \mathrm{y} \leq$ age $\leq 64 y$ & $-0.41 \pm 0.50$ & \\
\hline & Age $\geq 65 y$ & $-0.67 \pm 0.46$ & \\
\hline \multirow{2}{*}{ Gender } & Women & $-0.26 \pm 0.69$ & \multirow{2}{*}{$0.001^{2}$} \\
\hline & Men & $-0.40 \pm 0.54$ & \\
\hline \multirow{3}{*}{ Level of education } & Primary school & $-1.06 \pm 0.27$ & \multirow{3}{*}{$<0.0005$} \\
\hline & Secondary School & $-0.21 \pm 0.69$ & \\
\hline & University & $-0.38 \pm 0.60$ & \\
\hline \multirow{4}{*}{ Civil state } & Single & $-0.12 \pm 0.73$ & \multirow{4}{*}{$<0.0005^{1}$} \\
\hline & Married/Living together & $-0.44 \pm 0.55$ & \\
\hline & Divorced/Separated & $-0.31 \pm 0.62$ & \\
\hline & Widowed & $-0.54 \pm 0.38$ & \\
\hline \multirow{5}{*}{ Professional status } & Employed & $-0.41 \pm 0.57$ & \multirow{5}{*}{$<0.0005^{1}$} \\
\hline & Unemployed & $-0.40 \pm 0.76$ & \\
\hline & Student & $-0.08 \pm 0.74$ & \\
\hline & Retired & $-0.48 \pm 0.59$ & \\
\hline & Working student & $-0.19 \pm 0.52$ & \\
\hline \multirow{7}{*}{ Work or studies related areas } & Nutrition & $-0.22 \pm 0.74$ & \multirow{7}{*}{$<0.0005^{1}$} \\
\hline & Food & $-0.07 \pm 0.74$ & \\
\hline & Agriculture & $-0.30 \pm 0.64$ & \\
\hline & Sport & $-0.29 \pm 0.62$ & \\
\hline & Psychology & $0.19 \pm 0.91$ & \\
\hline & Health & $-0.21 \pm 0.74$ & \\
\hline & Others & $-0.38 \pm 0.58$ & \\
\hline
\end{tabular}

Note: ${ }^{1}$ - Kruskal-Wallis test for the comparison of 3 or more groups (Level of significance $5 \%$ ); ${ }^{2}$ - Mann-Whitney for comparison of 2 groups (Level of significance $5 \%$ )

In this study all mean scores for the different professional status had values between -0.5 and 0.5 , which indicates that independently of the profession, the participants' food choices were slightly influenced by emotional determinants. The results of the Kruskal-Wallis test showed that there were significant differences between the different professional statuses, concerning the influence that emotional determinants had on food choices. Those differences were between the retired and the students $(p=0.001)$, the employed and the working-students $(p=0.26)$ and also between the employed and the students $(\mathrm{p}<0.0005)$. 
As for the area of studies or work, it was observed that, despite the differences among the groups of the areas of study or work, all mean scores were higher than -0.5 and lower than 0.5 , which indicates that the food choices of those participants were slightly influenced by emotional determinants. The specific significant differences found, were between the participants, who had studies or professional activities in others areas and those who had studies or professional activity in the area of food $(\mathrm{p}<0.0005)$, and also between the participants, who had studies or professional activities in others areas and those, who had studies or professional activity in the area of psychology $(\mathrm{p}=0.019)$.

\section{3. 2. Anthropometric data and behavioural related elements}

As it can be seen in Table 7, as BMI increased, the influence that emotional determinants had on participants' food choices also increased, being the highest value for the obesity class (underweight: $-0.46 \pm 0.64$, normal weight: $-0.36 \pm 0.60$, overweight: $-0.01 \pm 0.76$, obesity: $0.18 \pm 0.76$ ). Furthermore, the results mean that, independently of the BMI class, the participant's food choices were slightly influenced by emotional determinants. Again there were found significant differences among the BMI classes, being those differences between the underweight and overweight classes $(p<0.0005)$, underweight and obesity classes $(p<0.0005)$, normal weight and overweight classes $(p<0.0005)$ and also between the normal weight and obesity classes $(p<0.0005)$.

\section{Table 7}

Relations between the anthropometric data and behavioural related elements and the emotional determinants (scale from $-2=$ food choices, not at all influenced by emotional determinants to $+2=$ food choices, strongly influenced by emotional determinants)

\begin{tabular}{|c|c|c|c|}
\hline \multicolumn{2}{|c|}{ Variable } & \multirow{2}{*}{$\frac{\operatorname{Mean} \pm \mathbf{S D}}{-0.460 .64 \pm}$} & \multirow{2}{*}{$\begin{array}{c}\text { p-value } \\
<0.0005^{1}\end{array}$} \\
\hline \multirow{4}{*}{ BMI class $\left(\mathrm{kg} / \mathrm{m}^{2}\right)$} & $\begin{array}{l}\text { Underweight } \\
(\mathrm{BMI}<18.50)\end{array}$ & & \\
\hline & $\begin{array}{c}\text { Normal weight } \\
(18.50 \leq \mathrm{BMI} \leq 24.99)\end{array}$ & $-0.360 .60 \pm$ & \\
\hline & $\begin{array}{c}\text { Overweight } \\
(25.00 \leq \mathrm{BMI} \leq 29.99)\end{array}$ & $-0.010 .76 \pm$ & \\
\hline & $\begin{array}{l}\text { Obesity } \\
(\geq 30.00)\end{array}$ & $0.180 .76 \pm$ & \\
\hline \multirow{8}{*}{ Specific food regimen } & Raw foodism & $-----^{2}$ & $0.001^{1}$ \\
\hline & Frutarianism & $-0.040 .83 \pm$ & \\
\hline & Vegetarianism & $-0.550 .73 \pm$ & \\
\hline & Veganism & $-1.100 .22 \pm$ & \\
\hline & Flexitarianism & $-0.140 .69 \pm$ & \\
\hline & Caloric restriction & $-0.180 .64 \pm$ & \\
\hline & Religion restrictions & $-0.650 .84 \pm$ & \\
\hline & Other & $-0.430 .75 \pm$ & \\
\hline \multirow{3}{*}{ Episode of any eating disorder } & No special regimen & $-0.300 .64 \pm$ & \\
\hline & Yes & $0.290 .83 \pm$ & \multirow{4}{*}{$<0.0005^{3}$} \\
\hline & No & $-0.360 .63 \pm$ & \\
\hline \multirow{5}{*}{ Eating disorders } & Bulimia & $0.380 .86 \pm$ & \\
\hline & Anorexia & $0.030 .86 \pm$ & \\
\hline & Binge-eating & $0.630 .79 \pm$ & \multirow[t]{3}{*}{$<0.0005^{1}$} \\
\hline & Other & $0.100 .53 \pm$ & \\
\hline & None & $-0.330 .63 \pm$ & \\
\hline
\end{tabular}

Note: ${ }^{1}$ - Kruskal-Wallis test for the comparison of 3 or more groups (Level of significance $5 \%$ ); ${ }^{2}-$ There were no occurrences; 3 - Mann-Whitney for comparison of 2 groups (Level of significance $5 \%$ ) 
Regarding the groups practising a specific food regimen, most of the mean scores, obtained for the influence of the emotional factors on the food choices, were between -0.5 and 0.5 , meaning that in those cases the participants' food choices were slightly influenced by emotional determinants. The exceptions were for the participants, who followed a vegetarian regimen $(-0.55 \pm 0.73)$ and for those, who had a food regimen, based on religion restrictions $(-0.65 \pm 0.84)$, which means that the food choices of those participants were not influenced by emotional determinants. To examine the differences in the influence of emotional determinants on food choices, based on the specific food regimens, Kruskal-Wallis test was conducted and the results revealed that there were significant differences, namely, between the vegans and the participants, who did not follow any specific food regimen $(\mathrm{p}=0.019)$, the vegans and the participants, who followed a caloric restriction $(\mathrm{p}=0.003)$, and also between the vegans and the flexitarians $(\mathrm{p}=0.012)$.

The results of this study showed significant differences, regarding the extent to which emotional determinants affected food choices, specifically between the participants, who already experienced an episode of any eating disorders and the ones, who never had. The highest mean score achieved was for the participants, who had already experienced a binge-eating episode $(0.63 \pm 0.79)$. For the other eating disorders' groups, the emotional determinants slightly influenced the food choices (average scores between -0.5 and 0.5 ). Furthermore, there were found significant differences across the eating disorders' groups, more specifically, the significant differences were between the participants that never had any eating disorder and the participants, who already experienced an episode of binge-eating $(\mathrm{p}<0.0005)$.

\section{Discussion}

In this work there was observed that an expressive part of the sample admitted that they consume foods for emotional reasons, such as for example foods that help relaxing and foods that make people feel good. On the other hand, the participants in this study do not appear to use food as emotional consolation, against loneliness, against boredom or as anti-depressive. These findings suggest that perhaps the participants were influenced by other aspects that make them feel good, not directly addressed in our questionnaire, or, even also in some cases people tend to deny to some extent (either consciously or unconsciously) the influence that emotional determinants had on their food choices. There are several factors that affect how people express their emotions, and in the field of eating, fear of others' criticism and shame itself, sometimes lead people to not be sincere about what they consume [37-39].

Age is a pivotal influencer in what comes to the influence of emotional determinants on food choices. In the case of the young, average and senior adults, their food choices were slightly influenced by emotional determinants, contrarily to the elderly, whose food choices were not influenced by emotional determinants. These findings are in line with the results of the study, developed by Wansink et al. [38], where it was observed, that younger people preferred more snack-related comfort foods, compared to those over 55 years old. In contrast, according to Pursey et al. [39], food addiction diagnosis tended to be higher in adults aged 35 years or over.

Also gender has been reported in multiple occasions to influence food choices, being in this study observed that women are more influenced by emotional determinants when making their food choices as compared to men. In the previous research it was also found, that restrained eating, dieting and eating disorders are much more common in women. In fact, women are more often affected by problems with their eating behaviour, such as craving for special foods, when compared to men [40].

According to van Strien et al. [41], high overconsumers are usually overweighted, have higher degrees of dietary restraint and also higher degrees of emotional and of external eating. They are also more often female and better educated. In this research it was observed, that the participants with different levels of scholar education had different behaviours towards food choices. This means that the food choices of the participants with secondary school and university degree were slightly influenced by emotional determinants. Nevertheless, the food choices of the participants with primary school as their terminal education, were not influenced by emotional determinants.

Relationships play an important role in people's life and influence their wellbeing, as well as their eating patterns, including the tendency to suffer from eating disorders [42]. According to pre- 
vious scientific works, emotional eating and overeating are more likely to occur when individuals are alone $[35,36]$. This trend was confirmed in the present study, with the single participants, showing the highest influence of emotions into their food choices. Widowhood is a stage of life, characterized by many emotional changes, which may lead to poor eating habits. Nevertheless, according to some authors widowers move between restoration and loss oriented behaviour [43-45], and most of them overcome the grief that had affected their appetite or increased meal skipping [46].

People experience different emotions throughout their lives and it is well established that emotions are associated with eating behaviour and more consumers today tend to choose foods they can emotionally resonate with $[47,48]$. For example, the unemployed appear to be particularly sad during episodes of job search, and they report feeling more sad during job search the longer they are unemployed [49]. In turn, sadness, stress and depression are often associated with eating behaviours that do not follow nutritional guidelines, such as, increased food intake or poor nutritional food choices [50]. In another study, it was suggested, that that emotional eaters, who are also highly active may still feel the urge to eat when under emotional distress, but they have the tendency to choose more healthy foods to cope with this distress [51]. However, in this study the participants' food choices were slightly influenced by emotional determinants, independently of the profession.

Considering the area of studies or work, no significant differences were highlighted by the results, obtained for students from nutrition and those from other areas. On the other hand, in a recent investigation, where it was compared the eating behaviour between Portuguese undergraduate nutrition students and students, attending other courses, and was observed, that nutrition students from both sexes had higher levels of flexible and also rigid control, when compared to students from other courses. The results also showed that female nutrition students presented higher binge-eating levels than their colleagues from other courses [52].

According to Frayn and Knäuper, approximately $60 \%$ or more of the overweight/obese adults are emotional eaters [53]. In this study, as BMI increased, the influence of emotional determinants on participants' food choices was becoming stronger, being highest for the participants with BMI of the obesity class. Furthermore, the results also showed that, independently of the BMI class, the participant's food choices were slightly influenced by emotional determinants.

Regarding the groups, practising a specific food regimen, most of the mean scores, obtained for the influence of the emotional factors on the food choices, were between -0.5 and 0.5 , meaning that in those cases the participants' food choices were slightly influenced by emotional determinants. The exceptions were for the participants, who followed a vegetarian regimen $(-0.55 \pm 0.73)$ and for those, who had a food regimen, based on religion restrictions $(-0.65 \pm 0.84)$, which means that the food choices of those participants were not influenced by emotional determinants. To examine the differences in the influence of emotional determinants on food choices, based on the specific food regimens, Kruskal-Wallis test was conducted and the results revealed that there were significant differences, namely, between the vegans and the participants who did not follow any specific food regimen $(\mathrm{p}=0.019)$, the vegans and the participants, who followed a caloric restriction $(\mathrm{p}=0.003)$, and also between the vegans and the flexitarians $(\mathrm{p}=0.012)$.

Emotions serve as a common trigger for binge episodes [54, 55], having this relation been proven in several studies [56-58]. The results of a recent study showed that eating due to positive and negative emotions was significantly related to binge-eating, restrained eating, and preoccupation with body image and weight [59]. In another study by Ricca et al. [12], it was observed, that emotional eating is also elevated in people, suffering from anorexia and bulimia nervosa. The results of this study corroborate those findings, and were found significant differences, regarding the extent to which emotional determinants affected food choices, between the participants, who already experienced an episode of any eating disorders and the ones, who never had. The highest mean score achieved was for the participants, who had already experienced a binge-eating episode, meaning that the food choices of those participants were influenced by emotional determinants. In the case of the other eating disorders' groups, it can be considered, that emotional determinants slightly influenced those participants' food choices.

Although this research highlighted some important trends as to how the Portuguese make their food choices and shape their eating behaviours, nonetheless there are some limitations that 
can be pointed out. One of the limitations relates to the fact that the sample at study was obtained by convenience, and therefore no equality was obtained for the number of elements in each of the classes for the variables at study. Such examples include higher number of participants from female gender as compared to men, or lower number of participants with the lowest level of education, primary school, as compared with higher levels of education. Another limitation was regarding the geographical area, considered for collecting the data, which was mainly the centre and North region of Portugal, with lowest representation of the south. Finally, perhaps the most important of the limitations was that this was a self-response questionnaire and because it deals with emotions, it is possible, that some participants might not exactly have answered in a true way when asked delicate questions about their emotional behaviours, like for example when they were asked if they suffered from eating disorders. It is known, that some people, who suffer from these diseases, tend to hide their condition and opt for a "denial" position. If this happened, we might have underestimated the dimension of the real problem in Portugal in the present day, but still the obtained results are valuable to understand many other aspects of people's food choices.

\section{Conclusion}

This study allowed obtaining interesting results, such as the fact that, in general, the participants' food choices were slightly influenced by emotional determinants. From the results obtained it can be concluded, that the particular characteristics of each individual affect the extent to which emotional determinants influence the participants' food choices. There were found significant differences in the influence that emotional determinants exerted on participants' food choices, regarding all the variables under study (age group, gender, level of education, civil state, professional status, work or studies related areas, BMI class and the fact that the participants had already experienced an episode of any eating disorder or not). Considering the sociodemographic factors, the lowest mean scores achieved were for the participants, who had the primary school as their final education, followed by the participants aged 65 or over, meaning that the food choices of those participants' were not influence by emotional determinants. For all the other cases, the participants' food choices were slightly influenced by emotional determinants, with the highest mean value for the participants that had studies or a professional activity, related to psychology. As for the BMI class, the highest mean score achieved was for the obese participants. Furthermore, there were found significant differences between the participants, who had already experienced an episode of any eating disorder and the ones, who never had, with a higher mean value for those, who had. The results also suggested that the food choices of the participants, that already experienced an episode of binge-eating, were more influenced by emotional determinants. For all the other eating disorders, the participants' food choices were only slightly influenced by emotional determinants.

Since emotional eating can lead to eating disorders and even to obesity, the results of this study are very relevant, because they highlighted the principal characteristics that can influence the extent to which emotional determinants influence people's food choices. This knowledge is very important for delineate and implement strategies, focused on the most problematic target audience, in order to prevent and reverse these eating behaviours.

The main limitation of this study is, perhaps, related to the fact that all responses have been self-reported and since this is a sensitive subject, which involves feelings such as guilt and fear of others' reaction, the responses, given by the participants, may not correspond exactly to the influence that the emotional determinants have on their food choices.

\section{Acknowledgment}

This work was prepared in the ambit of the multinational project EATMOT from CI\&DETS Research Centre (IPV - Viseu, Portugal) with reference PROJ/CI\&DETS/2016/0008 and also project PROJ/CI\&DETS/CGD/0012.

\section{Conflict of interest}

None to declare. 


\section{References}

[1] Pelletier, L. G., Dion, S. C., Slovinec-D’Angelo, M., Reid, R. (2004). Why Do You Regulate What You Eat? Relationships Between Forms of Regulation, Eating Behaviors, Sustained Dietary Behavior Change, and Psychological Adjustment. Motivation and Emotion, 28 (3), 245-277. doi: http://doi.org/10.1023/b:moem.0000040154.40922.14

[2] Lowe, M. R., Bocarsly, M. E., Parigi, A. D.; Harris, R. B. S., Mattes, R. D. (Eds.) (2008). Human eating motivation in times of plenty: biological, environmental and psychosocial influences. Appetite and Food Intake: Behavioral and Physiological Considerations. London: CRC Press, 376-394. doi: http://doi.org/10.1201/9781420047844.ch6

[3] Maddock, S., Hill, B. (2016). "Bagels and doughnuts ... round food for every mood" food advertising discourses. British Food Journal, 118 (2), 327-342. doi: http://doi.org/10.1108/bfj-04-2015-0136

[4] Macht, M., Simons, G. (2000). Emotions and eating in everyday life. Appetite, 35 (1), 65-71. doi: http://doi.org/10.1006/ appe. 2000.0325

[5] Macht, M. (2008). How emotions affect eating: A five-way model. Appetite, 50 (1), 1-11. doi: http://doi.org/10.1016/j.appet. 2007.07.002

[6] Gardner, M. P., Wansink, B., Kim, J., Park, S.-B. (2014). Better moods for better eating?: How mood influences food choice. Journal of Consumer Psychology, 24 (3), 320-335. doi: http://doi.org/10.1016/j.jcps.2014.01.002

[7] Spence, C. (2017). Comfort food: A review. International Journal of Gastronomy and Food Science, 9, 105-109. doi: http:// doi.org/10.1016/j.ijgfs.2017.07.001

[8] Locher, J. L., Yoels, W. C., Maurer, D., van Ells, J. (2006). Comfort Foods: An Exploratory Journey Into The Social and Emotional Significance of Food. Food and Foodways, 13 (4), 273-297. doi: http://doi.org/10.1080/07409710500334509

[9] Arnow, B., Kenardy, J., Agras, W.S. (1995). The Emotional Eating Scale: the development of a measure to assess coping with negative affect by eating. International Journal of Eating Disorders, 18 (1), 79-90. doi: http://doi.org/10.1002/1098108x(199507)18:1<79::aid-eat2260180109>3.0.co;2-v

[10] Litwin, R., Goldbacher, E. M., Cardaciotto, L., Gambrel, L. E. (2016). Negative emotions and emotional eating: the mediating role of experiential avoidance. Eating and Weight Disorders - Studies on Anorexia, Bulimia and Obesity, 22 (1), 97-104. doi: http://doi.org/10.1007/s40519-016-0301-9

[11] Nasirzadeh, Y., Kantarovich, K., Wnuk, S., Okrainec, A., Cassin, S. E., Hawa, R., Sockalingam, S. (2018). Binge Eating, Loss of Control over Eating, Emotional Eating, and Night Eating After Bariatric Surgery: Results from the Toronto Bari-PSYCH Cohort Study. Obesity Surgery, 28 (7), 2032-2039. doi: http://doi.org/10.1007/s11695-018-3137-8

[12] Ricca, V., Castellini, G., Fioravanti, G., Lo Sauro, C., Rotella, F., Ravaldi, C. et. al. (2012). Emotional eating in anorexia nervosa and bulimia nervosa. Comprehensive Psychiatry, 53 (3), 245-251. doi: http://doi.org/10.1016/j.comppsych.2011.04.062

[13] Annesi, J.J., Mareno, N., McEwen, K. (2016). Psychosocial predictors of emotional eating and their weight-loss treatment-induced changes in women with obesity. Eating and Weight Disorders, 21 (2), 289-295. doi: http://doi.org/10.1007/s40519-0150209-9

[14] Greeno, C. G., Wing, R. R. (1994). Stress-induced eating. Psychological Bulletin, 115 (3), 444-464. doi: http://doi.org/ 10.1037/0033-2909.115.3.444

[15] Oliver, G., Wardle, J., Gibson, E. L. (2000). Stress and Food Choice: A Laboratory Study. Psychosomatic Medicine, 62 (6), 853-865. doi: http://doi.org/10.1097/00006842-200011000-00016

[16] Aikman, S. N., Crites, S. L., Fabrigar, L. R. (2006). Beyond Affect and Cognition: Identification of the Informational Bases of Food Attitudes1. Journal of Applied Social Psychology, 36 (2), 340-382. doi: http://doi.org/10.1111/j.0021-9029.2006.00011.x

[17] Jackson, B., Lynne Cooper, M., Mintz, L., Albino, A. (2003). Motivations to eat: Scale development and validation. Journal of Research in Personality, 37 (4), 297-318. doi: http://doi.org/10.1016/s0092-6566(02)00574-3

[18] Lindeman, M., Väänänen, M. (2000). Measurement of ethical food choice motives. Appetite, 34 (1), 55-59. doi: http://doi.org/ 10.1006/appe.1999.0293

[19] Renner, B., Sproesser, G., Strohbach, S., Schupp, H. T. (2012). Why we eat what we eat. The Eating Motivation Survey (TEMS). Appetite, 59 (1), 117-128. doi: http://doi.org/10.1016/j.appet.2012.04.004

[20] Roininen, K., Lähteenmäki, L., Tuorila, H. (1999). Quantification of Consumer Attitudes to Health and Hedonic Characteristics of Foods. Appetite, 33 (1), 71-88. doi: http://doi.org/10.1006/appe.1999.0232

[21] Steptoe, A., Pollard, T. M., Wardle, J. (1995). Development of a Measure of the Motives Underlying the Selection of Food: the Food Choice Questionnaire. Appetite, 25 (3), 267-284. doi: http://doi.org/10.1006/appe.1995.0061

[22] van Strien, T., Frijters, J. E. R., Bergers, G. P. A., Defares, P. B. (1986). The Dutch Eating Behavior Questionnaire (DEBQ) for assessment of restrained, emotional, and external eating behavior. International Journal of Eating Disorders, 5 (2), $295-315$. doi: http://doi.org/10.1002/1098-108x(198602)5:2<295::aid-eat2260050209>3.0.co;2-t

[23] Witte, R., Witte, J. (2019). Statistics. New Jersey: Wiley, 1-576. 
[24] World health Organization: Global Database on Body Mass Index. Available at: https://www.who.int/nutrition/databases/bmi/en/

[25] Forrester-Knauss, C., Zemp Stutz, E. (2012). Gender differences in disordered eating and weight dissatisfaction in Swiss adults: Which factors matter? BMC Public Health, 12 (1). doi: http://doi.org/10.1186/1471-2458-12-809

[26] Kjelsås, E., Bjørnstrøm, C., Götestam, K. G. (2004). Prevalence of eating disorders in female and male adolescents (1415 years). Eating Behaviors, 5 (1), 13-25. doi: http://doi.org/10.1016/s1471-0153(03)00057-6

[27] Slof-Op 't Landt, M. C. T., van Furth, E. F., van Beijsterveldt, C. E. M., Bartels, M., Willemsen, G., de Geus, E. J. et. al. (2017). Prevalence of dieting and fear of weight gain across ages: a community sample from adolescents to the elderly. International Journal of Public Health, 62 (8), 911-919. doi: http://doi.org/10.1007/s00038-017-0948-7

[28] Liechty, J. M., Lee, M.-J. (2013). Longitudinal predictors of dieting and disordered eating among young adults in the U.S. International Journal of Eating Disorders, 46 (8), 790-800. doi: http://doi.org/10.1002/eat.22174

[29] Eneva, K. T., Murray, S., O’Garro-Moore, J., Yiu, A., Alloy, L. B., Avena, N. M., Chen, E. Y. (2017). Reward and punishment sensitivity and disordered eating behaviors in men and women. Journal of Eating Disorders, 5 (1). doi: http://doi.org/10.1186/ s40337-017-0138-2

[30] American Psychiatric Association (2013). Diagnostic and Statistical Manual of Mental Disorders, DSM-5. American Psychiatric Association, Washington.

[31] Davis, F. B. (1964). Educational Measurements and Their Interpretation. California: Wadsworth Publishing Company, 422.

[32] Duncan, A. E., Ziobrowski, H. N., Nicol, G. (2017). The Prevalence of Past 12-Month and Lifetime DSM-IV Eating Disorders by BMI Category in US Men and Women. European Eating Disorders Review, 25 (3), 165-171. doi: http://doi.org/10.1002/erv.2503

[33] Grucza, R. A., Przybeck, T. R., Cloninger, C. R. (2007). Prevalence and correlates of binge eating disorder in a community sample. Comprehensive Psychiatry, 48 (2), 124-131. doi: http://doi.org/10.1016/j.comppsych.2006.08.002

[34] Hudson, J. I., Hiripi, E., Pope, H. G., Kessler, R. C. (2007). The Prevalence and Correlates of Eating Disorders in the National Comorbidity Survey Replication. Biological Psychiatry, 61 (3), 348-358. doi: http://doi.org/10.1016/j.biopsych.2006.03.040

[35] Etkin, R. G., Bowker, J. C., Scalco, M. D. (2016). Associations between subtypes of social withdrawal and emotional eating during emerging adulthood. Personality and Individual Differences, 97, 239-244. doi: http://doi.org/10.1016/j.paid.2016.03.059

[36] Vesnaver, E., Keller, H. H., Sutherland, O., Maitland, S. B., Locher, J. L. (2015). Alone at the Table: Food Behavior and the Loss of Commensality in Widowhood: Table 1. The Journals of Gerontology Series B: Psychological Sciences and Social Sciences, 71 (6), 1059-1069. doi: http://doi.org/10.1093/geronb/gbv103

[37] Ford, P. A., Jaceldo-Siegl, K., Lee, J. W., Youngberg, W., Tonstad, S. (2013). Intake of Mediterranean foods associated with positive affect and low negative affect. Journal of Psychosomatic Research, 74 (2), 142-148. doi: http://doi.org/10.1016/j.jpsychores.2012.11.002

[38] Gilbert, J., Stubbs, R. J., Gale, C., Gilbert, P., Dunk, L., Thomson, L. (2014). A qualitative study of the understanding and use of "compassion focused coping strategies" in people who suffer from serious weight difficulties. Journal of Compassionate Health Care, 1 (1). doi: http://doi.org/10.1186/s40639-014-0009-5

[39] Hardman, R. K., Berrett, M. E., Richards, P. S., Black, S. (2014). Using Experiential Group Therapy in the Treatment of Eating Disorders. Eating Disorders, 23 (1), 89-97. doi: http://doi.org/10.1080/10640266.2014.940789

[40] Kiefer, I., Rathmanner, T., Kunze, M. (2005). Eating and dieting differences in men and women. The Journal of Men's Health \& Gender, 2 (2), 194-201. doi: http://doi.org/10.1016/j.jmhg.2005.04.010

[41] Faber, A., Dubé, L., Knäuper, B. (2018). Attachment and eating: A meta-analytic review of the relevance of attachment for unhealthy and healthy eating behaviors in the general population. Appetite, 123, 410-438. doi: http://doi.org/10.1016/j.appet. 2017.10.043

[42] Silverman, P.R. (2004). Widow to Widow: How the Bereaved Help One Another. New York: Brunner-Routledge, 282. doi: http://doi.org/10.4324/9780203020975

[43] Schut, M. S., Henk. (1999). The dual process model of coping with bereavement: rationale and description. Death Studies, 23 (3), 197-224. doi: http://doi.org/10.1080/074811899201046

[44] Vesnaver, E., Keller, H. H., Sutherland, O., Maitland, S. B., Locher, J. L. (2015). Food behavior change in late-life widowhood: A two-stage process. Appetite, 95, 399-407. doi: http://doi.org/10.1016/j.appet.2015.07.027

[45] Quandt, S. A., McDonald, J., Arcury, T. A., Bell, R. A., Vitolins, M. Z. (2000). Nutritional self-management of elderly widows in rural communities. The Gerontologist, 40 (1), 86-96. doi: http://doi.org/10.1093/geront/40.1.86

[46] Jiang, Y., King, J. M., Prinyawiwatkul, W. (2014). A review of measurement and relationships between food, eating behavior and emotion. Trends in Food Science \& Technology, 36 (1), 15-28. doi: http://doi.org/10.1016/j.tifs.2013.12.005

[47] Porcherot, C., Delplanque, S., Raviot-Derrien, S., Calvé, B. L., Chrea, C., Gaudreau, N., Cayeux, I. (2010). How do you feel when you smell this? Optimization of a verbal measurement of odor-elicited emotions. Food Quality and Preference, 21 (8), 938-947. doi: http://doi.org/10.1016/j.foodqual.2010.03.012 
[48] Krueger, A. B., Mueller, A. (2011). Job Search, Emotional Well-Being, and Job Finding in a Period of Mass Unemployment: Evidence from High-Frequency Longitudinal Data. Brookings Papers on Economic Activity, 2011 (1), 1-57. doi: http://doi.org/ 10.1353/eca.2011.0001

[49] Devonport, T. J., Nicholls, W., Fullerton, C. (2017). A systematic review of the association between emotions and eating behaviour in normal and overweight adult populations. Journal of Health Psychology, 24 (1), 3-24. doi: http://doi.org/ $10.1177 / 1359105317697813$

[50] Dohle, S., Hartmann, C., Keller, C. (2014). Physical activity as a moderator of the association between emotional eating and BMI: Evidence from the Swiss Food Panel. Psychology \& Health, 29 (9), 1062-1080. doi: http://doi.org/10.1080/08870446.20 14.909042

[51] Poínhos, R., Alves, D., Vieira, E., Pinhão, S., Oliveira, B. M. P. M., Correia, F. (2015). Eating behaviour among undergraduate students. Comparing nutrition students with other courses. Appetite, 84, 28-33. doi: http://doi.org/10.1016/j.appet.2014.09.011

[52] Frayn, M., Knäuper, B. (2017). Emotional Eating and Weight in Adults: a Review. Current Psychology, 37 (4), $924-933$. doi: http://doi.org/10.1007/s12144-017-9577-9

[53] Leehr, E. J., Krohmer, K., Schag, K., Dresler, T., Zipfel, S., Giel, K. E. (2015). Emotion regulation model in binge eating disorder and obesity - a systematic review. Neuroscience \& Biobehavioral Reviews, 49, 125-134. doi: http://doi.org/10.1016/ j.neubiorev.2014.12.008

[54] Péneau, S., Ménard, E., Méjean, C., Bellisle, F., Hercberg, S. (2013). Sex and dieting modify the association between emotional eating and weight status. The American Journal of Clinical Nutrition, 97 (6), 1307-1313. doi: http://doi.org/10.3945/ ajen.112.054916

[55] Braden, A., Musher-Eizenman, D., Watford, T., Emley, E. (2018). Eating when depressed, anxious, bored, or happy: Are emotional eating types associated with unique psychological and physical health correlates? Appetite, 125, 410-417. doi: http://doi.org/ 10.1016/j.appet.2018.02.022

[56] Pinaquy, S., Chabrol, H., Simon, C., Louvet, J.-P., Barbe, P. (2003). Emotional Eating, Alexithymia, and Binge-Eating Disorder in Obese Women. Obesity Research, 11 (2), 195-201. doi: http://doi.org/10.1038/oby.2003.31

[57] Ricca, V., Castellini, G., Lo Sauro, C., Ravaldi, C., Lapi, F., Mannucci, E. et. al. (2009). Correlations between binge eating and emotional eating in a sample of overweight subjects. Appetite, 53 (3), 418-421. doi: http://doi.org/10.1016/j.appet.2009.07.008

[58] Sultson, H., Kukk, K., Akkermann, K. (2017). Positive and negative emotional eating have different associations with overeating and binge eating: Construction and validation of the Positive-Negative Emotional Eating Scale. Appetite, 116, 423-430. doi: http://doi.org/10.1016/j.appet.2017.05.035 